\title{
Temporal and Spatial Variability of Precipitation from Observations and Models*
}

\author{
James H. Trammell, ${ }^{+}$Xun Jiang, ${ }^{+}$Liming Li, ${ }^{\#}$ Angela KaO, ${ }^{+}$GuAng J. Zhang,${ }^{@}$ \\ EDMUND K. M. CHANG, ${ }^{\&}$ AND YUK YUNG** \\ ${ }^{+}$Department of Earth and Atmospheric Sciences, University of Houston, Houston, Texas \\ ${ }^{\text {\# Department of Physics, University of Houston, Houston, Texas }}$ \\ ${ }^{@}$ Climate, Atmospheric Science and Physical Oceanography Division, Scripps Institution of Oceanography, \\ La Jolla, California \\ \& Institute for Terrestrial and Planetary Atmospheres, School of Marine and Atmospheric Sciences, Stony Brook University, \\ Stony Brook, New York \\ ** Division of Geological and Planetary Sciences, California Institute of Technology, Pasadena, California
}

(Manuscript received 6 May 2015, in final form 23 January 2016)

\begin{abstract}
Principal component analysis (PCA) is utilized to explore the temporal and spatial variability of precipitation from GPCP and a CAM5 simulation from 1979 to 2010. In the tropical region, the interannual variability of tropical precipitation is characterized by two dominant modes (El Niño and El Niño Modoki). The first and second modes of tropical GPCP precipitation capture $31.9 \%$ and $15.6 \%$ of the total variance, respectively. The first mode has positive precipitation anomalies over the western Pacific and negative precipitation anomalies over the central and eastern Pacific. The second mode has positive precipitation anomalies over the central Pacific and negative precipitation anomalies over the western and eastern Pacific. Similar variations are seen in the first two modes of tropical precipitation from a CAM5 simulation, although the magnitudes are slightly weaker than in the observations. Over the Northern Hemisphere (NH) high latitudes, the first mode, capturing $8.3 \%$ of the total variance of NH GPCP precipitation, is related to the northern annular mode (NAM). During the positive phase of NAM, there are negative precipitation anomalies over the Arctic and positive precipitation anomalies over the midlatitudes. Over the Southern Hemisphere (SH) high latitudes, the first mode, capturing $13.2 \%$ of the total variance of SH GPCP precipitation, is related to the southern annular mode (SAM). During the positive phase of the SAM, there are negative precipitation anomalies over the Antarctic and positive precipitation anomalies over the midlatitudes. The CAM5 precipitation simulation demonstrates similar results to those of the observations. However, they do not capture both the high precipitation anomalies over the northern Pacific Ocean or the position of the positive precipitation anomalies in the SH.
\end{abstract}

\section{Introduction}

Precipitation can be influenced by different factors, such as atmospheric temperature, circulation, and clouds (Trenberth and Shea 2005; Adler et al. 2008; Allan and Soden 2008; Liu et al. 2009; Li et al. 2011; Bony et al. 2013). In response to global warming, global

\footnotetext{
* Supplemental information related to this paper is available at the Journals Online website: http://dx.doi.org/10.1175/JCLI-D-150325.s1.

Corresponding author address: Xun Jiang, Dept. of Earth and Atmospheric Sciences, University of Houston, 4800 Calhoun Rd., Houston, TX 77004.

E-mail: xjiang7@uh.edu
}

mean precipitation is found to increase with a slower trend than the total mass of the water vapor (Allen and Ingram 2002; Adler et al. 2003; Held and Soden 2006; Gu et al. 2007; Adler et al. 2008; Stephens and Ellis 2008; Li et al. 2011). In addition to the global mean precipitation, some studies (Chou and Neelin 2004; Allan and Soden 2007; Chou et al. 2009; Li et al. 2011; Durack et al. 2012; Polson et al. 2013; Chou et al. 2013; Trammell et al. 2015) explored precipitation variations over different regions and found that precipitation has an increasing tendency in the wet areas and has a decreasing tendency in the dry areas. In addition to the external forcing, changes in the precipitation can also be attributed to natural climate variability, such as El Niño and Pacific decadal variability (Smith et al. 2006; Ashok et al. 2007; Gu and Adler 2012; Marvel and Bonfils 2013). Using 
annual average precipitation data, Smith et al. (2006) found that most variations in precipitation are related to El Niño-Southern Oscillation. Gu and Adler (2012) found that the Pacific decadal variability could also influence precipitation variations. In this paper, we will analyze the variability of precipitation over the tropics, the Northern Hemisphere (NH) high latitudes, and the Southern Hemisphere (SH) high latitudes, respectively. Moreover, we will compare the precipitation variations between observations and model simulations. These analyses can help us to better understand precipitation variability in different regions and identify if a current model can successfully simulate precipitation variations.

\section{Data and model}

Precipitation data are utilized from the Global Precipitation Climatology Project (GPCP) (Adler et al. 2003; Huffman et al. 2009), which is an international project designed to construct the global long-term record of precipitation on behalf of the World Meteorological Organization (WMO), the World Climate Research Programme (WCRP), and the Global Energy and Water Cycle Experiment (GEWEX) (Huffman et al. 1997). The GPCP version 2.2 precipitation dataset, derived from satellite and gauge measurements, is available from 1979 to the present. GPCP incorporates data from emission and scattering estimates from SSM/I and SSMIS instruments, GPI and outgoing longwave radiation (OLR) precipitation index (OPI) estimates and rain gauge analysis, and TOVS and Atmospheric Infrared Sounder (AIRS) estimates (Huffman and Bolvin 2012). The combined GPCP satellite-based precipitation dataset is adjusted by the rain gauge analysis (Adler et al. 2003). Since there are no surface rain gauge data available over the Antarctic region, GPCP precipitation data rely mainly on satellite data and have less constraint from in situ rain gauge data over the Antarctic (Huffman et al. 2009). Most areas of the Antarctic have low values of precipitation, so the lack of rain gauge data over the Antarctic will not greatly influence the results. GPCP version 2.2 precipitation data are provided by the NOAA/OAR/ESRL Physical Sciences Division (PSD) and can be downloaded online (http://www.esrl.noaa.gov/ $\mathrm{psd} /$ data/gridded/data.gpcp.html). The spatial resolution of the data is $2.5^{\circ} \times 2.5^{\circ}$ in latitude/longitude.

Geopotential height data are used to explore the connection between precipitation variability and atmospheric dynamics. Data from the National Centers for Environmental Prediction-U.S. Department of Energy (NCEPDOE) AMIP-II reanalysis (NCEP-2; Kanamitsu et al. 2002) for geopotential height are used. The resolution of the NCEP-2 geopotential height data is $2.5^{\circ} \times 2.5^{\circ}$.
In addition to the GPCP precipitation and NCEP-2 geopotential height datasets, we have performed a simulation using the National Center for Atmospheric Research (NCAR) Community Atmosphere Model, version 5 (CAM5), for the period of 1979-2010 in this research. CAM5 is the atmospheric component of the Community Earth System Model, version 1 (CESM1). In CAM5, the radiation scheme incorporates the Rapid Radiative Transfer Model for GCMs (RRTMG; Iacono et al. 2008). The moist boundary layer is parameterized using the Bretherton and Park (2009) scheme, and the large-scale cloud and precipitation processes are parameterized with a prognostic two-moment bulk cloud microphysics scheme (Morrison and Gettelman 2008). Shallow convection is parameterized using Park and Bretherton (2009), and deep convection is parameterized using the Zhang and McFarlane (1995) convection scheme with a dilution approximation for the calculation of convective available potential energy (Neale et al. 2008). The CAM5 simulation uses observed sea surface temperature as part of the lower boundary conditions, with a horizontal resolution of $2.5^{\circ} \times 1.9^{\circ}$. For comparison, we have also examined precipitation from the GISS-E2-R AMIP-type simulations from phase 5 of CMIP (CMIP5), which are available from the CMIP5 archives (Taylor et al. 2012). Observed sea surface temperatures are used to drive the GISS-E2-R model (hereafter GISS model) with a horizontal resolution of $2.5^{\circ} \times 2^{\circ}$ (Shindell et al. 2013).

\section{Methodology}

To explore the temporal and spatial variability of precipitation, the linear trend is first removed from the time series between 1979 and 2010. Seasonal cycles for each time series are extracted, and a low-pass filter is applied to the precipitation anomaly to remove the high-frequency oscillation. The filter is constructed as the convolution of a step function with a Hanning window and was chosen to obtain a full signal from periods above 15 months and no signal from periods below 12.5 months (Jiang et al. 2004). Then, the principal component analysis (PCA) (Richman 1986; Preisendorfer 1988; Thompson and Wallace 2000; Camp et al. 2003; Jiang et al. 2008a; Jiang et al. 2008b) is applied to the detrended, deseasonalized, and low-passfiltered precipitation data from GPCP and CAM5.

PCA provides a decomposition of a multivariate dataset into empirical orthogonal functions (EOFs), with associated time-dependent amplitude, known as principal component (PC) time series. The EOFs are the Eigenfunctions of the covariance matrix of the dataset sorted by the decreasing values of associated Eigen values. Since these Eigen values represent the variance captured by each EOF, PCA guarantees that the leading $n$ EOFs capture more of the total 

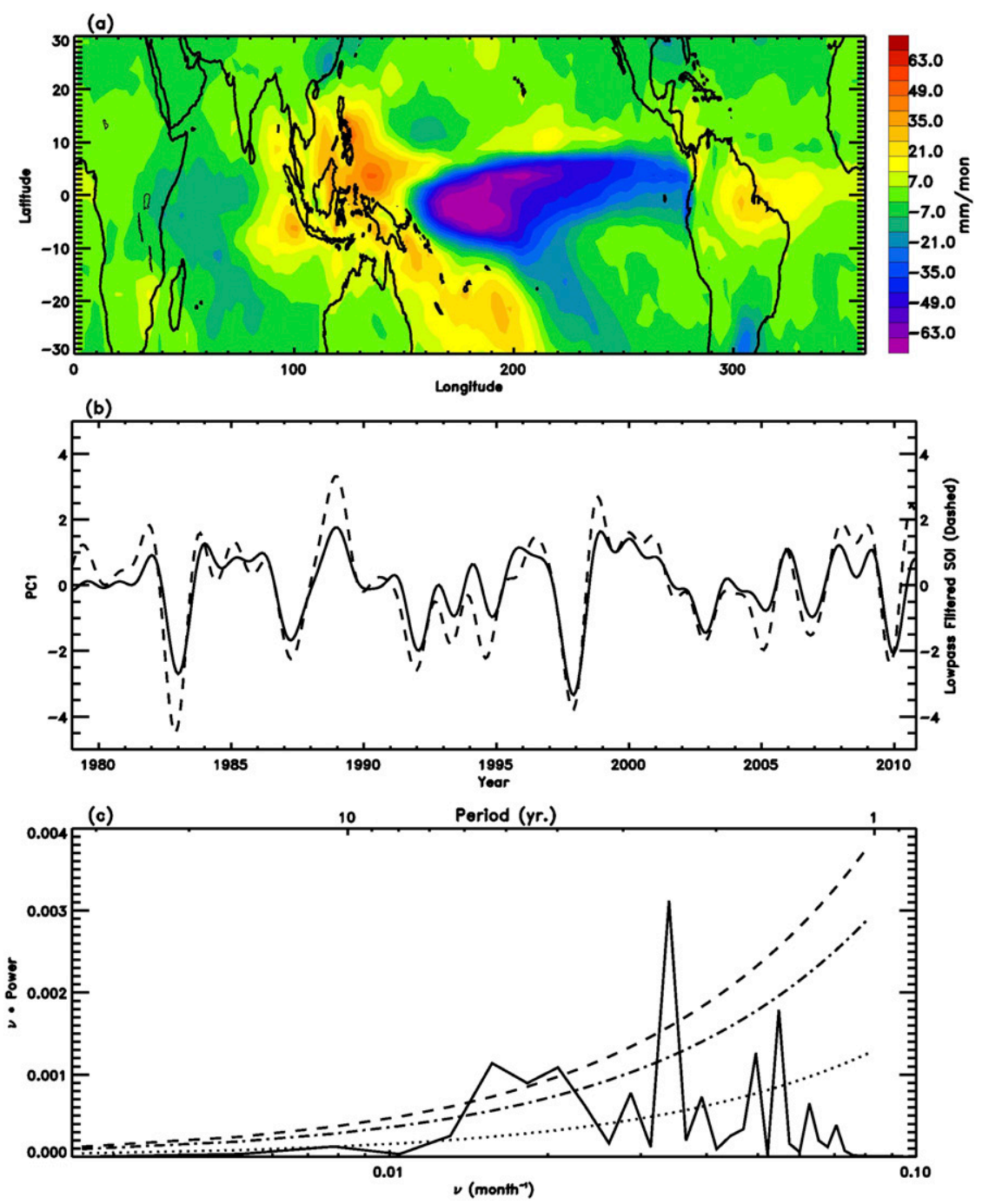

FIG. 1. (a) The spatial pattern of the first mode of the GPCP precipitation anomalies in the tropics (mm month ${ }^{-1}$ ). (b) PC1 of the tropical GPCP precipitation (solid line) and the lowpass-filtered SOI (dashed line). The correlation coefficient is 0.90 ( $0.1 \%$ significance level). (c) Power spectral estimate of PC1. The first mode explains $31.9 \%$ of the total variance.

variance of the dataset than any other $n$ orthogonal vectors. However, PCA is not a scale-independent method. Therefore, it is necessary to weigh each element of the covariance matrix by the area it represents; that is, we scale each time series by the square root of the area $\left[(\cos \theta)^{1 / 2}\right.$, where $\theta$ is the latitude], prior to constructing the covariance matrix (Baldwin et al. 2009). Eigenfunctions of the covariance matrix of the dataset are the EOFs, with associated timedependent amplitude PC time series. To recover the spatial patterns for the original (unscaled) precipitation anomaly, a multiple linear regression is performed for each grid point, using as predictors the PC time series. The resulting linear regression coefficients are the spatial patterns of the precipitation variability associated with the $i$ th PC time series.

\section{PCA results of GPCP and model precipitation}

\section{a. Results for tropical precipitation}

\section{1) Results FOR GPCP PRECIPITATION IN THE TROPICS}

PCA is utilized to analyze the interannual variability of the GPCP precipitation in the tropics $\left(30^{\circ} \mathrm{N}-30^{\circ} \mathrm{S}\right)$. The first leading mode accounts for $31.9 \%$ of the total variance of the GPCP tropical precipitation anomalies. The spatial pattern of the precipitation anomalies regressed on the first PC is shown in Fig. 1a. There are positive precipitation anomalies over the western Pacific and negative precipitation anomalies over the central 
and eastern Pacific. Values range from $60 \mathrm{~mm}$ month $^{-1}$ in the western Pacific and $-60 \mathrm{~mm}$ month $^{-1}$ in the central and eastern Pacific. The spatial pattern is similar to the first mode of the global annual GPCP precipitation anomalies (Smith et al. 2006) and the relationship between the GPCP rainfall anomalies and the Niño-3 index (Ashok et al. 2007). The Southern Oscillation index (SOI) is used to calculate the correlation between ENSO and PC1. A positive SOI represents La Niña events, while a negative SOI illustrates El Niño events. For a fair comparison, a low-pass filter is applied to the detrended SOI. The correlation between the time series of the detrended and low-pass-filtered SOI and the first mode (PC1) of the GPCP tropical precipitation anomalies is very high, reaching 0.90 , shown in Fig. $1 \mathrm{~b}$. The corresponding significance level is $0.1 \%$. The significance statistics for the correlations were generated by using a Monte Carlo method (Press et al. 1992; Jiang et al. 2004). During La Niña months, there are positive precipitation anomalies over the western Pacific and negative precipitation anomalies over the central and eastern Pacific. During El Niño months, there are negative precipitation anomalies over the western Pacific and positive precipitation anomalies over the central and eastern Pacific. A power spectral analysis is also applied to PC1. The power spectrum of the PC1, shown in Fig. 1c, demonstrates strong spectral peaks near 2-7yr, similar to those in ENSO. The statistical significance of the signals in a power spectrum is obtained by comparing the amplitude of a spectral peak to the red noise spectrum (Gilman et al. 1963). The red noise spectrum used in constructing the null hypothesis for significance is the spectrum associated with the autocorrelation function (Gilman et al. 1963; Jiang et al. 2008a). The 90\% and $95 \%$ confidence intervals for the power spectrum are found using $F$ statistics to compare the spectrum to the red noise spectrum (Jiang et al. 2008a).

The second leading mode accounts for $15.6 \%$ of the total variance of the GPCP tropical precipitation anomalies. Illustrated in Fig. 2a is the spatial pattern of the precipitation anomalies regressed on the second PC of the GPCP tropical precipitation. There are positive precipitation anomalies over the central Pacific and negative precipitation anomalies over the western and eastern Pacific. Values range from $60 \mathrm{~mm} \mathrm{month}{ }^{-1}$ in the central Pacific to $-40 \mathrm{~mm}$ month $^{-1}$ in the western and eastern Pacific. The El Niño Modoki index (EMI) is used to calculate the correlation between the phenomenon known as El Niño Modoki and the second PC time series, which is demonstrated in Fig. 2b. EMI is defined as the second principal component time series of the tropical Pacific sea surface temperature anomaly (SSTA) (Ashok et al. 2007). A low-pass filter is then applied to the detrended EMI time series. The correlation coefficient between the detrended and low-passfiltered EMI and PC2 of the GPCP precipitation anomalies is 0.77 (at a $0.1 \%$ significance level), suggesting that the second mode of the GPCP tropical precipitation anomalies is related to El Niño Modoki. During the positive phase of El Niño Modoki, there are more positive SSTAs over the central Pacific than the western and eastern Pacific, which will bring more precipitation to the central Pacific than to the western and eastern Pacific. During the negative phase of El Niño Modoki, the SSTA is negative over the central Pacific, which can lead to negative precipitation anomalies over the region. The power spectrum of the PC2 time series, shown in Fig. 2c, demonstrates $90 \%$ significant spectral peaks at 2.6 and $8.5 \mathrm{yr}$.

\section{2) RESUltS FOR MODEL PRECIPITATION IN THE TROPICS}

PCA is now applied to the CAM5 precipitation over the tropics $\left(30^{\circ} \mathrm{N}-30^{\circ} \mathrm{S}\right)$ to investigate if the model can correctly simulate the influence of ENSO and El Niño Modoki on precipitation. The first leading mode accounts for $24.3 \%$ of the total variance of CAM5 tropical precipitation anomalies. Illustrated in Fig. 3a is the spatial pattern of the CAM5 precipitation anomalies regressed on the first PC of CAM5 precipitation over the tropics. This mode demonstrates a pattern similar to the leading mode of the observed GPCP precipitation anomalies, although the magnitudes are somewhat underpredicted. Comparison of the time series of the detrended and lowpass-filtered SOI and the PC1 of the CAM5 tropical precipitation anomalies is shown in Fig. 3b. The correlation coefficient between the two time series is $0.87(0.1 \%$ significance level). Additionally, the PC1 of the CAM5 tropical precipitation anomalies correlates well with the PC1 of the GPCP tropical precipitation anomalies with a correlation coefficient of 0.94 ( $0.1 \%$ significance level). The power spectrum of the PC1 of the CAM5 tropical precipitation anomalies, shown in Fig. 3c, demonstrates strong spectral peaks between 2 and $7 \mathrm{yr}$. Similar analyses are applied to GISS model AMIP-type CMIP5 simulations. The leading mode of the GISS model tropical precipitation anomalies captures $25.2 \%$ of the total variance. It has a similar spatial pattern to the first mode of the GPCP tropical precipitation anomalies. However, there are some discrepancies over the western Pacific Ocean and in the magnitudes. PC1 of the GISS model tropical precipitation correlates well with the detrended and low-pass-filtered SOI index with a correlation coefficient of 0.8 ( $0.1 \%$ significance level).

The second mode of the CAM5 tropical precipitation anomalies captures $11.6 \%$ of the total variance in the 

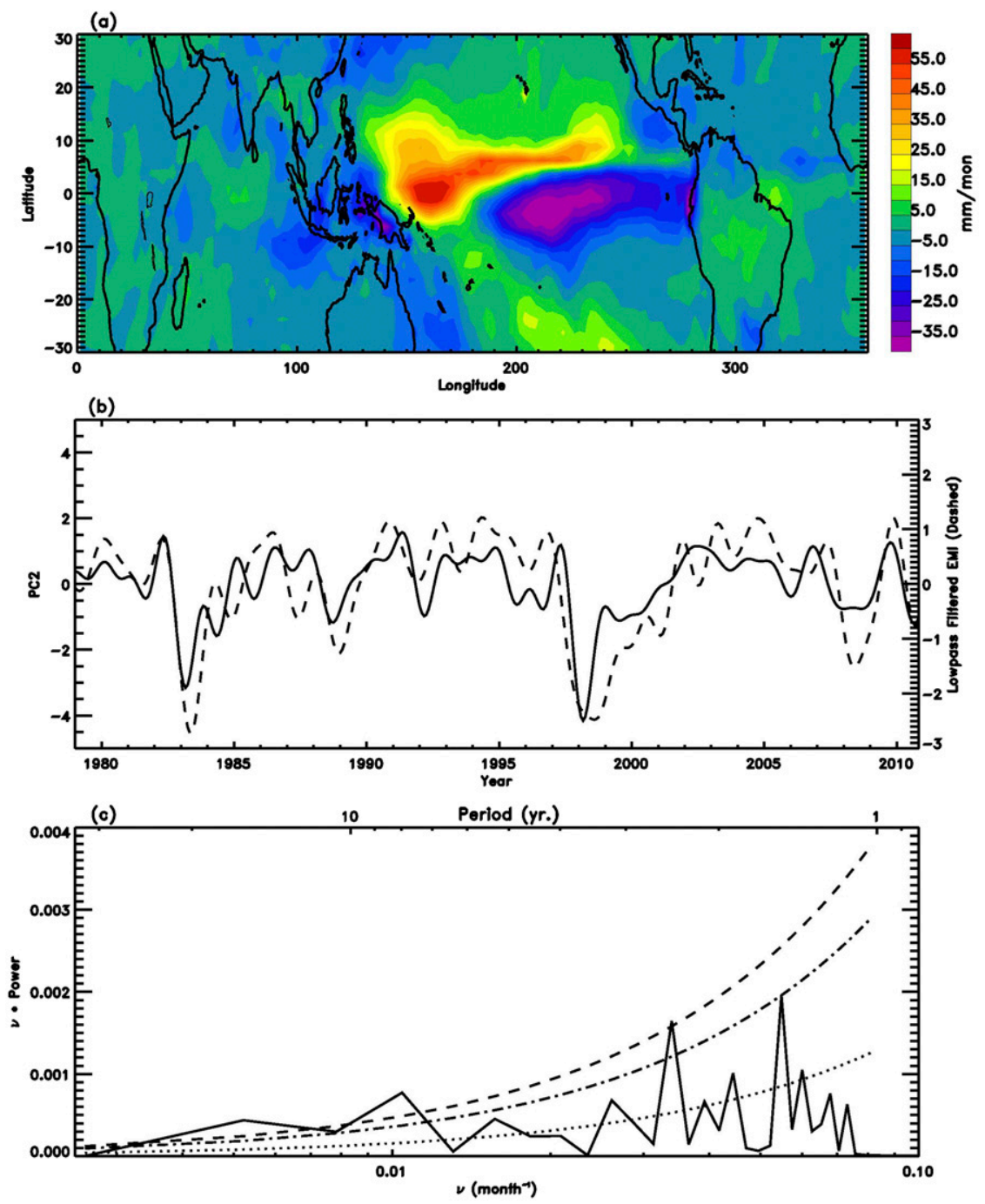

FIG. 2. (a) The spatial pattern of the second mode of the GPCP precipitation anomalies in the tropics (mm month ${ }^{-1}$ ). (b) PC2 of the tropical GPCP precipitation (solid line) and low-passfiltered EMI (dashed line). The correlation coefficient is 0.77 ( $0.1 \%$ significance level). (c) Power spectral estimate of PC2. The second mode explains $15.6 \%$ of the total variance.

CAM5 tropical precipitation anomalies. Illustrated in Fig. 4a is the spatial pattern of the CAM5 precipitation anomalies regressed on the second PC of the CAM5 tropical precipitation anomalies. This mode demonstrates a pattern similar to that of the observed GPCP second mode but, again, with weaker magnitudes. The correlation coefficient between PC2 and low-pass and detrended EMI is 0.74 ( $0.1 \%$ significance level), as illustrated in Fig. $4 \mathrm{~b}$. Like the first mode, PC2 of the CAM5 tropical precipitation anomalies correlates well with PC2 of the GPCP tropical precipitation anomalies, with a correlation coefficient of 0.89 ( $0.1 \%$ significance level). The power spectrum of $\mathrm{PC} 2$ of the CAM5 tropical precipitation anomalies, shown in Fig. 4c, reveals $90 \%$ significant spectral peaks at $2.5,5-6$, and $8 \mathrm{yr}$. The second mode of the GISS model tropical precipitation anomalies captures $9.6 \%$ of the total variances. It is similar to the spatial pattern of the second mode of the GPCP tropical precipitation anomalies, although there are some differences in the magnitudes. PC2 of the GISS model tropical precipitation correlates well with the detrended and low-pass-filtered EMI with a correlation coefficient of 0.7 ( $0.1 \%$ significance).

In summary, the precipitation signals in both El Niño and El Niño Modoki are well captured in the CAM5 simulation. However, the magnitudes of the first two modes in CAM5 are weaker than the observations. Similar analyses have also been applied to the GISS model simulations. The GISS model simulates El Niño and El Niño Modoki signals reasonably well, but there are some differences in the magnitudes. 

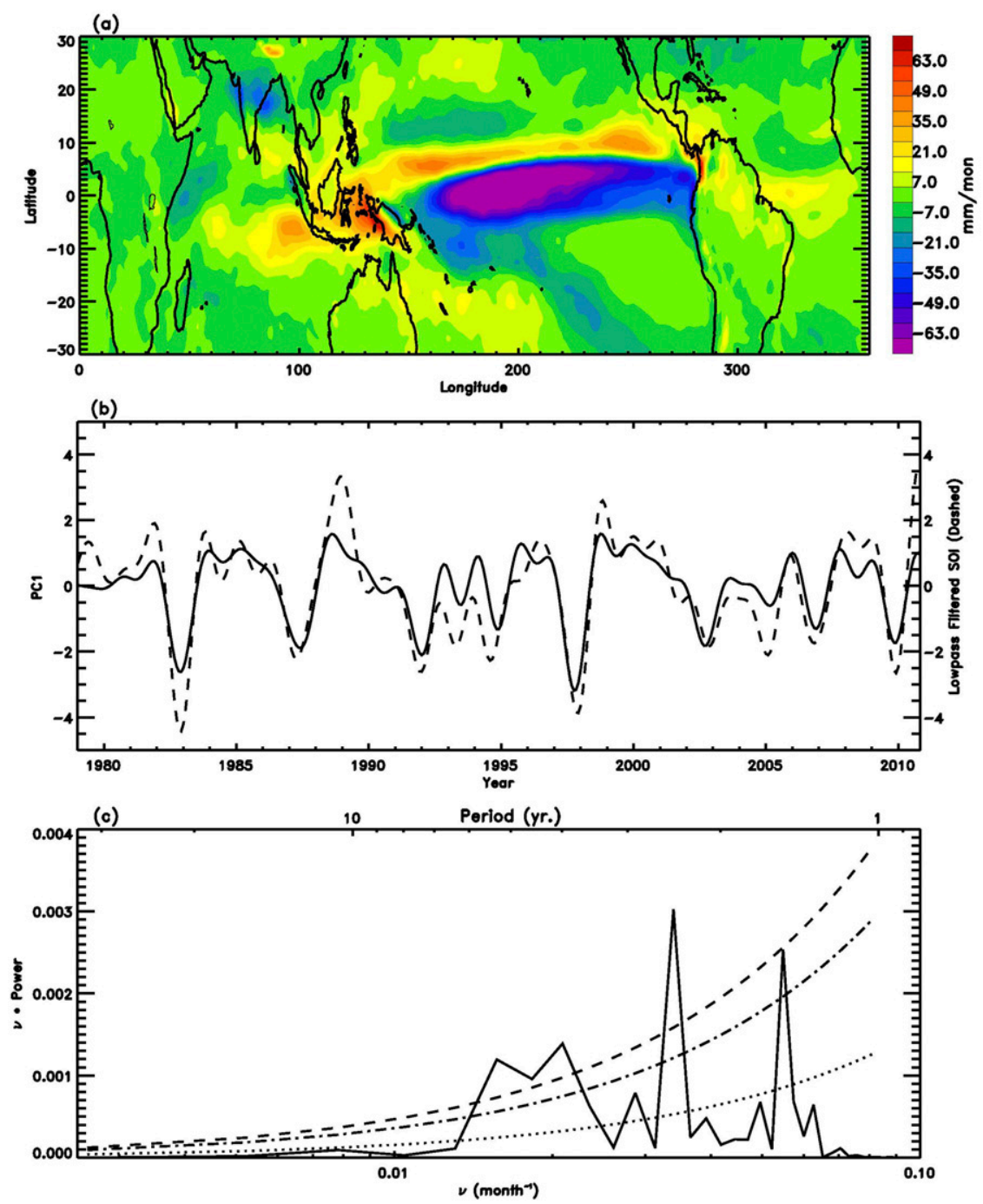

FIG. 3. (a) The spatial pattern of the first mode of the CAM5 precipitation anomalies in the tropics $\left(\mathrm{mm} \mathrm{month}^{-1}\right)$. (b) PC1 of the tropical CAM5 precipitation (solid line) and the lowpass-filtered SOI (dashed line). The correlation coefficient is 0.87 ( $0.1 \%$ significance level).

(c) Power spectral estimate of PC1. The first mode explains $24.3 \%$ of the total variance.

\section{b. Results for precipitation over NH high latitudes}

\section{1) RESULTS FOR GPCP PRECIPITATION OVER NH HIGH LATITUDES}

PCA is utilized to analyze the interannual variability of the GPCP precipitation anomalies in the NH high latitudes $\left(30^{\circ}-90^{\circ} \mathrm{N}\right)$. The first mode accounts for $8.3 \%$ of the total variance of GPCP precipitation anomalies in the NH high latitudes. The polar projection of the spatial pattern of the precipitation anomalies regressed upon PC1 of the GPCP precipitation anomalies is shown in Fig. 5a. The first mode is approximately zonally symmetric and the center is slightly off the North Pole. It exhibits negative precipitation anomalies in the polar region and positive precipitation anomalies in the midlatitudes, which coincide with the storm track regions. As shown in Fig. S1a of the supplementary material, the positive precipitation anomalies are related to the storm track activities calculated as the variance in sea level pressure (Chang and Fu 2002). The temporal behavior of $\mathrm{PC} 1$ in the $\mathrm{NH}$ is shown in Fig. 5b. For comparison, the $300-\mathrm{hPa}$ northern annular mode (NAM) index is overlaid as a dashed line. The NAM index is the PC associated with the first leading mode, capturing $14.7 \%$ of the total variance, for the NCEP-2 geopotential height at $300 \mathrm{hPa}$ from 1979 to 2010 (Baldwin and Dunkerton 1999; Thompson and Wallace 2000). The 

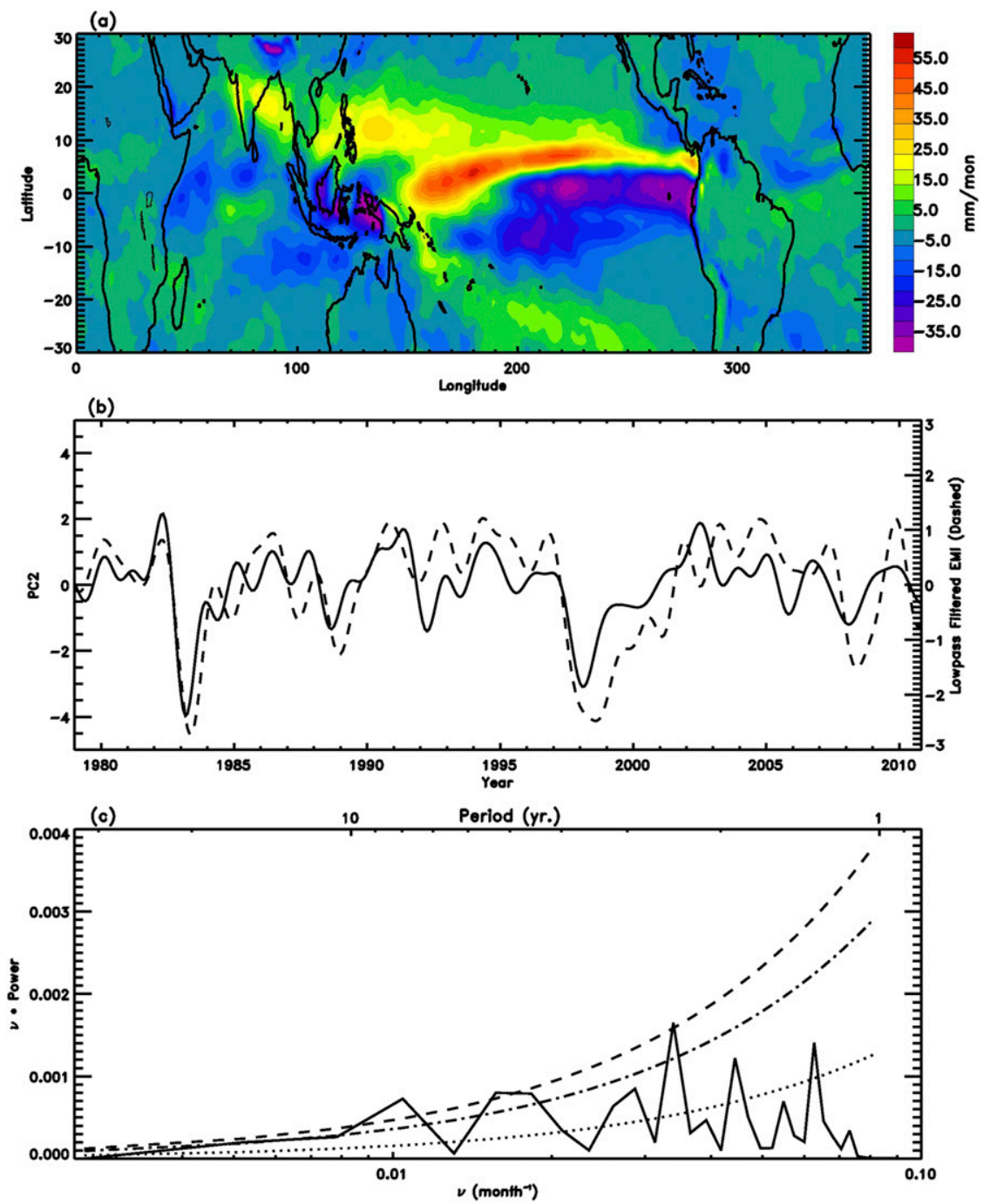

FIG. 4. (a) The spatial pattern of the second mode of the CAM5 precipitation anomalies in the tropics (mm month ${ }^{-1}$ ). (b) PC2 of the tropical CAM5 precipitation (solid line) and the lowpass-filtered EMI (dashed line). The correlation coefficient is 0.74 ( $0.1 \%$ significance level). (c) Power spectral estimate of PC2. The second mode explains $11.6 \%$ of the total variance.

correlation coefficient between the detrended $\mathrm{PC} 1$ and the detrended and low-pass-filtered NAM index is $0.50(0.1 \%$ significance level). When the polar vortex is stronger and the NAM index is positive, there are negative precipitation anomalies over the polar region and positive precipitation anomalies over the midlatitudes. The power spectrum of $\mathrm{PC} 1$ of the precipitation anomalies over the NH high latitudes in Fig. $5 \mathrm{c}$ reveals $90 \%$ significant spectral peaks at 17 months, 32 months, and 8 years.

\section{2) RESULTS FOR CAM5 PRECIPITATION OVER NH HIGH LATITUDES}

PCA is next applied to the CAM5 precipitation over the $\mathrm{NH}$ high latitudes $\left(30^{\circ}-90^{\circ} \mathrm{N}\right)$ to investigate if the model can correctly simulate the variability in the high latitudes. The leading mode accounts for $8.2 \%$ of the total variance of the CAM5 precipitation anomalies in the NH high latitudes. Illustrated in Fig. 6a is the spatial pattern of the CAM5 precipitation anomalies regressed on the first PC of the CAM5 precipitation anomalies in the NH high latitudes. This mode demonstrates patterns similar to those of the observed GPCP leading mode, although it does not capture the high precipitation anomalies over the Pacific Ocean. To explore the possible relationship between this mode and the polar vortex simulated in CAM5, the leading mode and PC of the CAM5 300-hPa geopotential height anomalies are calculated from 1979 to 2010 . The detrended and 
(a)
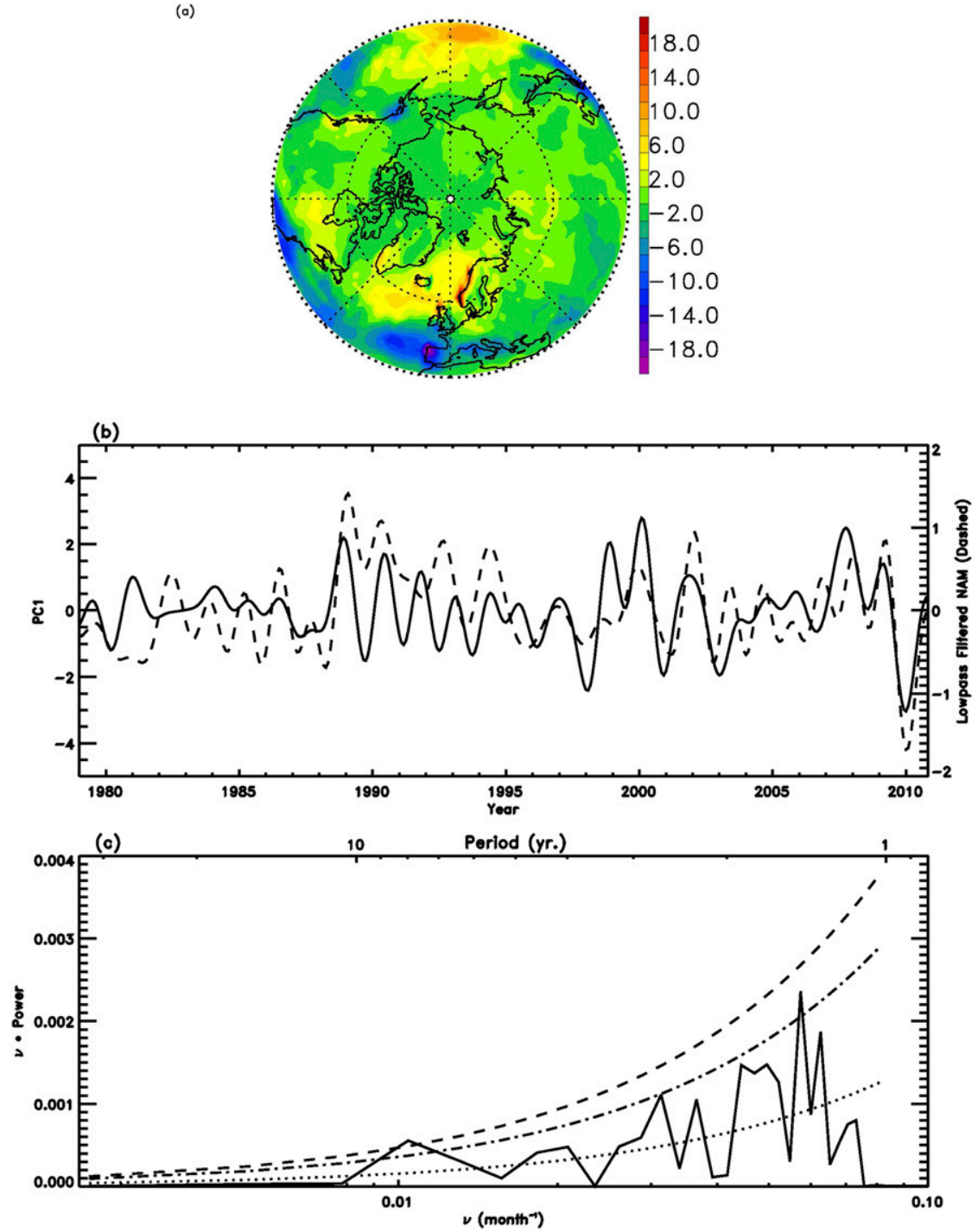

FIG. 5. (a) The spatial pattern of the first mode of the GPCP precipitation anomalies in the NH $\left(\mathrm{mm} \mathrm{month}^{-1}\right.$ ). (b) PC1 of the NH GPCP precipitation (solid line) and the 300-hPa low-passfiltered NAM index (dashed line). The correlation coefficient is 0.50 ( $0.1 \%$ significance level).

(c) Power spectral estimate of PC1. The first mode explains $8.3 \%$ of the total variance.

low-pass-filtered PC1 of CAM5 300-hPa geopotential height anomalies is overlaid with PC1 of the CAM5 precipitation anomalies in Fig. 6b. The correlation between the two time series is $0.80(0.1 \%$ significance level). Additionally, the model PC1 correlates well with GPCP PC1 with a correlation coefficient of $0.44(0.1 \%$ significance level). The power spectrum of the PC1 mode, shown in Fig. 6c, demonstrates $90 \%$ significant spectral peaks at 30 months and 8 years. A similar analysis is applied to the GISS model precipitation over the NH high latitudes. The first mode of the GISS precipitation anomalies over the $\mathrm{NH}$ high latitudes captures $8.8 \%$ of the total variance. It has a similar spatial pattern to the first mode of the GPCP precipitation anomalies. However, it has some difficulty in simulating the positive precipitation anomalies over the northern Pacific Ocean. PC1 of GISS model NH precipitation has a weak correlation with $\mathrm{PC} 1$ of GPCP NH precipitation, showing a correlation of 0.39 ( $1 \%$ significance).

\section{c. Results for precipitation over SH high latitudes}

\section{1) RESUlTS FOR GPCP PRECIPITATION OVER SH HIGH LATITUDES}

In the $\mathrm{SH}$, the first mode accounts for $13.2 \%$ of the total variance, as illustrated in Fig. 7a. The first mode is 
(a)
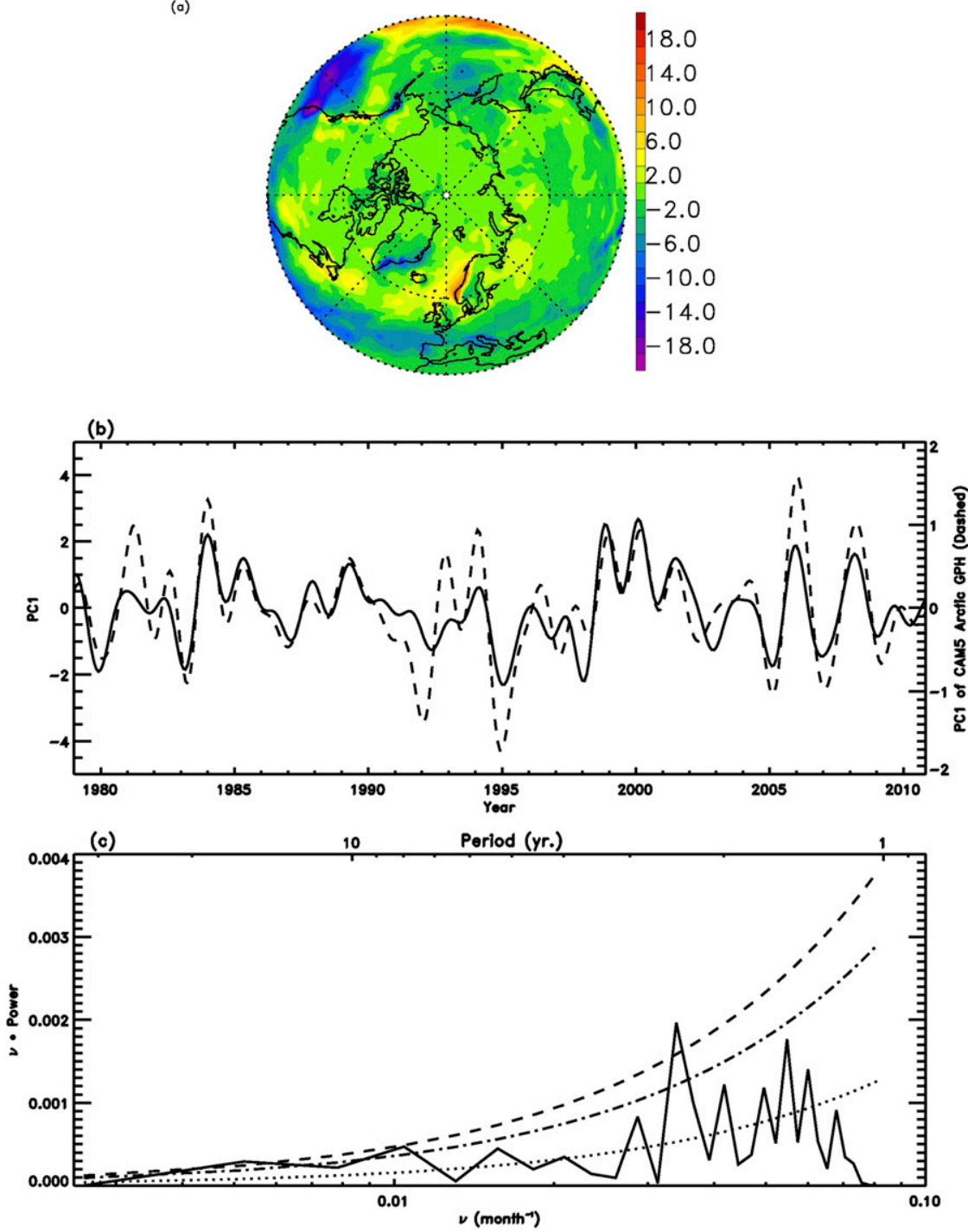

FIG. 6. (a) The spatial pattern of the first mode of the CAM5 precipitation anomalies in the NH $\left(\mathrm{mm} \mathrm{month}^{-1}\right.$ ). (b) PC1 of the NH CAM5 precipitation (solid line) and PC1 of the CAM5 300-hPa geopotential height (dashed line). The correlation coefficient is 0.8 ( $0.1 \%$ significance level). (c) Power spectral estimate of PC1. The first mode explains $8.2 \%$ of the total variance.

zonally symmetric and strongly resembles the first mode in the $\mathrm{NH}$; it is associated with the southern annular mode (SAM; Thompson and Wallace 2000). The first mode has negative precipitation anomalies in the polar region and positive precipitation anomalies in the midlatitudes. The positive precipitation anomalies coincide with the positive storm track anomalies over the South Pacific Ocean, as shown in Fig. S1b of the supplementary material. PC1 of the GPCP precipitation anomalies over the SH high latitudes is compared with the lowpass-filtered 300-hPa SAM index (dotted line) in Fig. 7b. The correlation coefficient between the detrended PC1 and detrended and low-pass-filtered SAM index is $0.4(0.7 \%$ significance level). A stronger polar vortex in the $\mathrm{SH}$ (positive SAM index) will lead to less precipitation in the SH high latitudes. The power spectrum of the detrended $\mathrm{PC} 1$ in Fig. $7 \mathrm{c}$ reveals $90 \%$ significant peaks at 30 months, 4 years, and 10 years.

\section{2) RESUlTS FOR CAM5 PRECIPITATION OVER SH HIGH LATITUDES}

PCA is then applied to the CAM5 precipitation over the $\mathrm{SH}$ high latitudes $\left(30^{\circ}-90^{\circ} \mathrm{S}\right)$ to investigate if the model can correctly simulate the variability in the $\mathrm{SH}$ high latitudes. The first leading mode accounts for $10.3 \%$ of the total variance of the CAM5 precipitation 
(a)
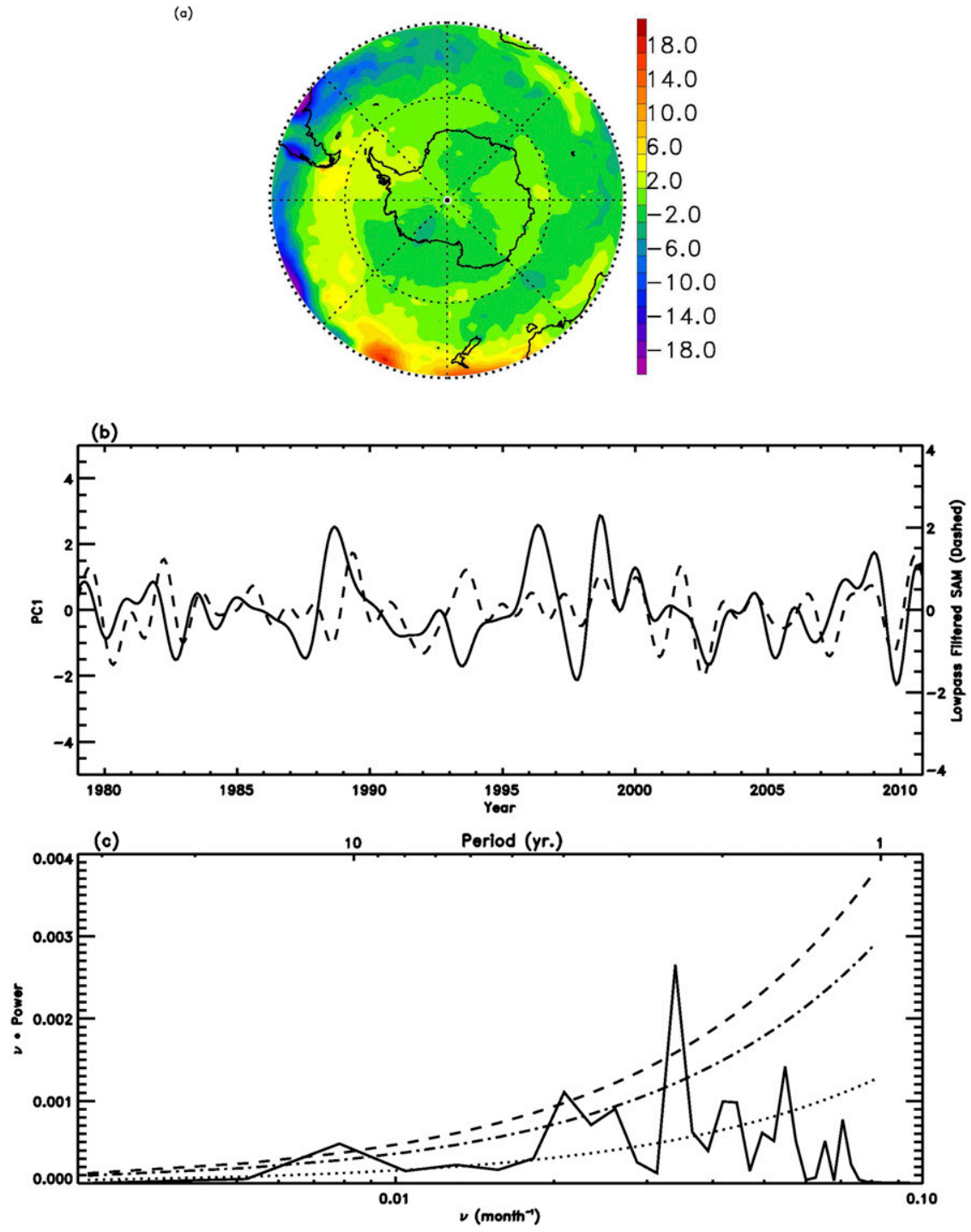

FIG. 7. (a) The spatial pattern of the first mode of the GPCP precipitation anomalies in the $\mathrm{SH}\left(\mathrm{mm} \mathrm{month}^{-1}\right)$. (b) PC1 of the SH GPCP precipitation (solid line) and the $300-\mathrm{hPa}$ SAM index (dashed line). The correlation coefficient is 0.40 ( $0.4 \%$ significance level). (c) Power spectral estimate of PC1. The first mode explains $13.2 \%$ of the total variance.

anomalies over the $\mathrm{SH}$ high latitudes. Illustrated in Fig. 8a is the spatial pattern of the CAM5 precipitation anomalies regressed on the first PC of the CAM5 precipitation anomalies over the SH high latitudes. This mode demonstrates patterns similar to those of the observed GPCP leading mode, although the positions for the positive precipitation anomalies are slightly different than in the observations. Comparison of the time series of $\mathrm{PC} 1$ of the CAM5 precipitation anomalies over the SH high latitudes and PC1 of the CAM5 300-hPa geopotential height anomalies reveals a good correlation coefficient of 0.5 ( $0.1 \%$ significance level), as shown in Fig. 8b. Furthermore, the model PC1 corresponds well with the PC1 of the $30^{\circ}-90^{\circ} \mathrm{S}$ GPCP data, with a correlation coefficient of 0.75 (0.1\% significance level). The power spectrum of the PC1, depicted in Fig. 8c, demonstrates 90\% significant spectral peaks at 22 months, 3.5 years, and 11 years. A similar analysis is applied to the GISS model precipitation over the SH high latitudes. The first mode of GISS model SH precipitation captures $12.3 \%$ of the total variance. It has a similar spatial pattern to the first mode of the GPCP $\mathrm{SH}$ precipitation anomalies, yet it cannot simulate the positions of the positive precipitation anomalies well. The correlation coefficient between PC1 of the GISS model $\mathrm{SH}$ precipitation anomalies and $\mathrm{PC} 1$ of the GPCP SH precipitation anomalies is $0.6(0.1 \%$ significance $)$. 
(a)
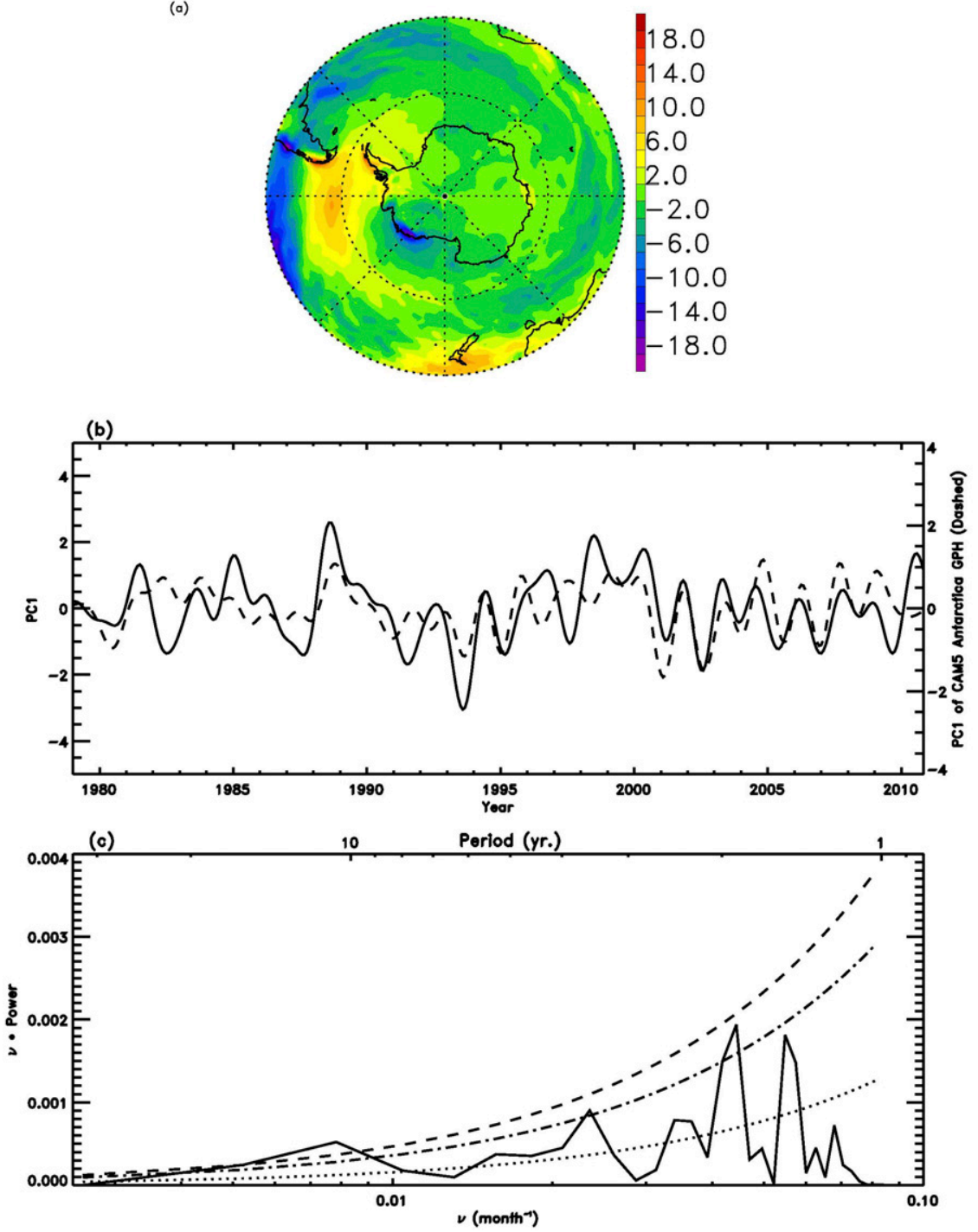

FIG. 8. (a) The spatial pattern of the first mode of the CAM5 precipitation anomalies in the SH $\left(\mathrm{mm} \mathrm{month}^{-1}\right.$ ). (b) PC1 of the SH CAM5 precipitation (solid line) and PC1 of the CAM5 300-hPa geopotential height (dashed line). The correlation coefficient is 0.5 ( $0.1 \%$ significance level). (c) Power spectral estimate of PC1. The first mode explains $10.3 \%$ of the total variance.

\section{Conclusions and discussion}

PCA has been applied to GPCP precipitation data and a CAM5 simulation over the tropics, NH high latitudes, and SH high latitudes. The first leading mode of tropical GPCP precipitation anomalies, capturing $31.9 \%$ of the total variance, illustrates positive precipitation anomalies over the western Pacific and negative precipitation anomalies over the central and eastern Pacific, which is related to La Niña and El Niño. The correlation coefficient between PC1 of the tropical GPCP precipitation anomalies and SOI is 0.9 . The second leading mode of tropical GPCP precipitation anomalies, capturing $15.6 \%$ of the total variance, demonstrates positive precipitation anomalies over the central Pacific and negative precipitation anomalies over the western and eastern Pacific, which can be explained by the unique tripolar nature of the SSTA caused by El Niño Modoki. The correlation between PC2 of tropical GPCP precipitation anomalies and EMI is 0.75 . The results of the tropical precipitation anomalies from CAM5 are similar to those of the observed GPCP, although magnitudes are somewhat underestimated for both modes.

The first leading mode of the GPCP precipitation anomalies over $30^{\circ}-90^{\circ} \mathrm{N}$ is approximately zonally symmetric, with negative precipitation anomalies in the polar region and positive precipitation anomalies in the 
midlatitudes, which is related to NAM. The correlation coefficient between PC1 of the NH high-latitude GPCP precipitation anomalies and NAM is 0.5. When a stronger polar vortex exists, the NAM index is positive, and there are negative precipitation anomalies over the Arctic and positive precipitation anomalies over the $\mathrm{NH}$ midlatitudes. The leading mode of the $30^{\circ}-90^{\circ} \mathrm{S}$ GPCP precipitation anomalies is associated with the southern annular mode (SAM). When the SAM index is positive, there is less precipitation over the Antarctic and more precipitation over the $\mathrm{SH}$ midlatitudes. The CAM5 precipitation simulation demonstrates patterns similar to those of the observed GPCP, yet they do not capture the high precipitation anomalies over the NH Pacific Ocean and the position of the positive precipitation anomalies is slightly different in the SH. Similar analyses are also applied to AMIP-type CMIP5 simulations from the GISS model. Both CAM5 and the GISS model can simulate the precipitation reasonably well, except that the first mode of the GISS model precipitation anomalies in the $\mathrm{NH}$ high latitudes has a relatively weak correlation with PC1 of the GPCP precipitation. This result suggests that the observed sea surface temperature is important for the correct simulation of precipitation at different regions. Nevertheless, some of the differences between the observed and modeled precipitation patterns in the middle and high latitudes may be due to different internal variabilities that are present in the observations and in the AMIP runs (Coats et al. 2013).

In addition to the sea surface temperature, CAM5 is also very effective in simulating the clouds, which is crucial for an accurate representation of precipitation in different regions. Results revealed from this study can help us to better understand the dominant variability of precipitation over the tropics, the Arctic, and the Antarctic. By comparing the leading modes between observations and models, we can identify possible deficiencies in the model simulations, which are important for correct simulations and predictions of precipitation extremes in the future.

Acknowledgments. We thank two anonymous reviewers and the editor for helpful comments. XJ and YLY are supported by the OCO-2 project, NASA Grant NNX13AK34G NASA, and ROSES-2010 NEWS Grant NNX13AC04G. LL is supported by NASA ROSES Cassini Data Analysis Program.

\section{REFERENCES}

Adler, R. F., and Coauthors, 2003: The version 2 Global Precipitation Climatology Project (GPCP) monthly precipitation analysis (1979-present). J. Hydrometeor., 4, 1147-1167, doi:10.1175/1525-7541(2003)004<1147:TVGPCP>2.0.CO;2.
—, G. J. Gu, J. J. Wang, G. J. Huffman, S. Curtis, and D. Bolvin, 2008: Relationships between global precipitation and surface temperature on interannual and longer timescales (1979-2006). J. Geophys. Res., 113, D22104, doi:10.1029/2008JD010536.

Allan, R. P., and B. J. Soden, 2007: Large discrepancy between observed and simulated precipitation trends in the ascending and descending branches of the tropical circulation. Geophys. Res. Lett., 34, 187-205, doi:10.1029/2007GL031460.

$\longrightarrow$, and - 2008: Atmospheric warming and the amplification of precipitation extremes. Science, 321, 1481-1484, doi:10.1126/ science. 1160787.

Allen, M. R., and W. J. Ingram, 2002: Constraints on future changes in climate and the hydrological cycle. Nature, 419, 224-232, doi:10.1038/nature01092.

Ashok, K., S. K. Behera, S. A. Rao, H. Weng, and T. Yamagata, 2007: El Niño Modoki and its possible teleconnection. J. Geophys. Res., 112, C11007, doi:10.1029/2006JC003798.

Baldwin, M. P., and T. J. Dunkerton, 1999: Propagation of the Arctic Oscillation from the stratosphere to the troposphere. J. Geophys. Res., 104, 30 937-30 946, doi:10.1029/1999JD900445.

_ D. B. Stephenson, and I. T. Jolliffe, 2009: Spatial weighting and iterative projection methods for EOFs. J. Climate, 22, 234-243, doi:10.1175/2008JCLI2147.1.

Bony, S., G. Bellon, D. Klocke, S. Sherwood, S. Fermepin, and S. Denvil, 2013: Robust direct effect of carbon dioxide on tropical circulation and regional precipitation. Nat. Geosci., 6 , 447-451, doi:10.1038/ngeo1799.

Bretherton, C. S., and S. Park, 2009: A new moist turbulence parameterization in the Community Atmosphere Model. J. Climate, 22, 3422-3448, doi:10.1175/2008JCLI2556.1.

Camp, C. D., M. S. Roulston, and Y. L. Yung, 2003: Temporal and spatial patterns of the interannual variability of total ozone in the tropics. J. Geophys. Res., 108, 4643, doi:10.1029/ 2001JD001504.

Chang, E. K. M., and Y. Fu, 2002: Interdecadal variations in Northern Hemisphere winter storm track intensity. J. Climate, 15, 642-658, doi:10.1175/1520-0442(2002)015<0642:IVINHW>2.0.CO;2.

Chou, C., and J. D. Neelin, 2004: Mechanisms of global warming impacts on regional tropical precipitation. J. Climate, 17, 2688-2701, doi:10.1175/1520-0442(2004)017<2688:MOGWIO>2.0.CO;2.

,,-- C. A. Chen, and J. Y. Tu, 2009: Evaluating the "richget-richer" mechanism in tropical precipitation change under global warming. J. Climate, 22, 1982-2005, doi:10.1175/ 2008JCLI2471.1.

— J. C. H. Chiang, C. Lan, C. Chung, Y. Liao, and C. Lee, 2013: Increase in the range between wet and dry season precipitation. Nat. Geosci., 6, 263-267, doi:10.1038/ngeo1744.

Coats, S., J. E. Smerdon, B. I. Cook, and R. Seager, 2013: Stationarity of the tropical pacific teleconnection to North America in CMIP5/PMIP3 model simulations. Geophys. Res. Lett., 40, 4927-4932, doi:10.1002/grl.50938.

Durack, P. J., S. E. Wijffels, and R. J. Matear, 2012: Ocean salinities reveal strong global water cycle intensification during 1950 to 2000. Science, 336, 455-458, doi:10.1126/science.1212222.

Gilman, D. L., F. J. Fuglister, and J. M. Mitchell, 1963: On the power spectrum of red noise. J. Atmos. Sci., 20, 182-184, doi:10.1175/1520-0469(1963)020<0182:OTPSON >2.0.CO;2.

Gu, G. J., and R. F. Adler, 2012: Interdecadal variability/longterm changes in global precipitation patterns during the past three decades: Global warming and/or Pacific decadal variability. Climate Dyn., 40, 3009-3022, doi:10.1007/ s00382-012-1443-8. 
G. J. Huffman, and S. Curtis, 2007: Tropical rainfall variability on interannual-to-interdecadal and longer time scales derived from the GPCP monthly product. J. Climate, $\mathbf{2 0}$, 4033-4046, doi:10.1175/JCLI4227.1.

Held, I. M., and B. J. Soden, 2006: Robust responses of the hydrological cycle to global warming. J. Climate, 19, 5686-5699, doi:10.1175/JCLI3990.1.

Huffman, G. J., and D. T. Bolvin, 2012: GPCP version 2.2 combined precipitation data set. NCDC, Asheville, NC, 46 pp. [Available online at ftp://precip.gsfc.nasa.gov/pub/gpcp-v2.2/ doc/V2.2_doc.pdf.]

_ - and Coauthors, 1997: The Global Precipitation Climatology Project (GPCP) Combined Precipitation dataset. Bull. Amer. Meteor. Soc., 78, 5-20, doi:10.1175/1520-0477(1997)078<0005: TGPCPG $>2.0 . \mathrm{CO} ; 2$.

- R. F. Adler, D. T. Bolvin, and G. J. Gu, 2009: Improvements in the GPCP global precipitation record: GPCP version 2.1. Geophys. Res. Lett., 36, L17808, doi:10.1029/2009GL040000.

Iacono, M. J., J. S. Delamere, E. J. Mlawer, M. W. Shephard, S. A. Clough, and W. D. Collins, 2008: Radiative forcing by longlived greenhouse gases: Calculations with the AER radiative transfer models. J. Geophys. Res., 113, D13103, doi:10.1029/ 2008JD009944.

Jiang, X., C. D. Camp, R. Shia, D. Noone, C. Walker, and Y. L. Yung, 2004: Quasi-biennial oscillation and quasi-biennial oscillation-annual beat in the tropical total column ozone: A two-dimensional model simulation. J. Geophys. Res., 109, D16305, doi:10.1029/2003JD004377.

— - and Coauthors, 2008a: Interannual variability and trends in extratropical ozone. Part I: Northern Hemisphere. J. Atmos. Sci., 65, 3013-3029, doi:10.1175/2008JAS2665.1.

_ extratropical ozone. Part II: Southern Hemisphere. J. Atmos. Sci., 65, 3030-3041, doi:10.1175/2008JAS2793.1.

Kanamitsu, M., W. Ebisuzaki, J. Woollen, S. Yang, J. J. Hnillo, M. Fiorino, and G. L. Potter, 2002: NCEP-DOE AMIP-II Reanalysis (R-2). Bull. Amer. Meteor. Soc., 83, 1631-1643, doi:10.1175/BAMS-83-11-1631.

Li, L., X. Jiang, M. T. Chahine, E. T. Olsen, E. J. Fetzer, L. Chen, and Y. L. Yung, 2011: The recycling rate of atmospheric moisture over the past two decades (1988-2009). Environ. Res. Lett., 6, 1-6.

Liu, S. C., C. B. Fu, C. J. Shiu, J. P. Chen, and F. T. Wu, 2009: Temperature dependence of global precipitation extremes. Geophys. Res. Lett., 36, L17702, doi:10.1029/2009GL040218.

Marvel, K., and C. Bonfils, 2013: Identifying external influences on global precipitation. Proc. Natl. Acad. Sci. USA, 110, 1930119306, doi:10.1073/pnas.1314382110.

Morrison, H., and A. Gettelman, 2008: A new two-moment bulk stratiform cloud microphysics scheme in the Community Atmosphere Model, version 3 (CAM3). Part I: Description and numerical tests. J. Climate, 21, 3642-3659, doi:10.1175/ 2008JCLI2105.1.

Neale, R. B., J. H. Richter, and M. Jochum, 2008: The impact of convection on ENSO: From a delayed oscillator to a series of events. J. Climate, 21, 5904-5924, doi:10.1175/ 2008JCLI2244.1.

Park, S., and C. S. Bretherton, 2009: The University of Washington shallow convection and moist turbulence schemes and their impact on climate simulations with the Community Atmosphere Model. J. Climate, 22, 3449-3469, doi:10.1175/ 2008JCLI2557.1.

Polson, D., G. C. Hegerl, R. P. Allan, and B. Balan Sarojini, 2013: Have greenhouse gases intensified the contrast between wet and dry regions? Geophys. Res. Lett., 40, 47834787, doi:10.1002/grl.50923.

Preisendorfer, R. W., 1988: Principal Component Analysis in Meteorology and Oceanography. Developments in Atmospheric Sciences, Vol. 17, Elsevier, 425 pp.

Press, W., S. Teukolsky, W. Vetterling, and B. Flannery, 1992: Numerical Recipes in Fortran 77: The Art of Scientific Computing. Cambridge University Press, 933 pp.

Richman, M. B., 1986: Rotation of principal components. J. Climatol., 6, 293-335, doi:10.1002/joc.3370060305.

Shindell, D. T., and Coauthors, 2013: Radiative forcing in the ACCMIP historical and future climate simulations. Atmos. Chem. Phys., 13, 2939-2974, doi:10.5194/acp-13-2939-2013.

Smith, T., X. Yin, and A. Gruber, 2006: Variations in annual global precipitation (1979-2004), based on the Global Precipitation Climatology Project $2.5^{\circ}$ analysis. Geophys. Res. Lett., 33, L06705, doi:10.1029/2005GL025393.

Stephens, G. L., and T. D. Ellis, 2008: Controls of global-mean precipitation increases in global warming GCM experiments. J. Climate, 21, 6141-6155, doi:10.1175/2008JCLI2144.1.

Taylor, K. E., R. J. Stouffer, and G. A. Meehl, 2012: An overview of CMIP5 and the experiment design. Bull. Amer. Meteor. Soc., 93, 485-498, doi:10.1175/BAMS-D-11-00094.1.

Thompson, D. W. J., and J. M. Wallace, 2000: Annular modes in the extratropical circulation. Part I: Month-to-month variability. J. Climate, 13, 1000-1016, doi:10.1175/1520-0442(2000)013<1000: AMITEC $>2.0 . C O ; 2$.

Trammell, J. H., X. Jiang, L. Li, M. Liang, M. Li, J. Zhou, E. Fetzer, and Y. Yung, 2015: Investigation of precipitation variations over wet and dry areas from observation and model. $A d v$. Meteor., 2015, 981092, doi:10.1155/2015/981092.

Trenberth, K. E., and D. J. Shea, 2005: Relationships between precipitation and surface temperature. Geophys. Res. Lett., 32, L14703, doi:10.1029/2005GL022760.

Zhang, G. J., and N. A. McFarlane, 1995: Sensitivity of climate simulations to the parameterization of cumulus convection in the Canadian Climate Centre general circulation model. Atmos.-Ocean, 33, 407-446, doi:10.1080/07055900.1995.9649539. 